\title{
Investigation of Performance and Combustion Characteristics of DI Diesel Engine Fuelled with Ternary Fuel Blend at Different Injection Pressure
}

\author{
Pani Sharanappa, Mallinath C. Navindgi \\ Department of Mechanical Engineering, PDA College of Engineering, Kalburgi, India \\ Email: spani_8800@yahoo.co.in
}

How to cite this paper: Sharanappa, P. and Navindgi, M.C. (2017) Investigation of Performance and Combustion Characteristics of DI Diesel Engine Fuelled with Ternary Fuel Blend at Different Injection Pressure. World Journal of Engineering and Technology, 5, 125-138.

https://doi.org/10.4236/wjet.2017.51011

Received: January 9, 2017

Accepted: February 25, 2017

Published: February 28, 2017

Copyright $\odot 2017$ by authors and Scientific Research Publishing Inc. This work is licensed under the Creative Commons Attribution International License (CC BY 4.0).

http://creativecommons.org/licenses/by/4.0/

\begin{abstract}
The depletion of fossil diesel fuels, global warming concerns and strict limits on regulated pollutant emissions are encouraging the use of renewable fuels. Biodiesel is the most used renewable fuel in compression ignition (CI) engine. The majority of literature agrees that the particulate matter (PM), unburnt total hydrocarbons (THC) and carbon dioxide (CO) emission from biodiesel are lower than from conventional diesel fuel. One of the most important reasons for this is the oxygen content of the biodiesel. This induces a more complete and cleaner combustion process. In addition to this the absence of aromatic compounds in biodiesel leads to particulate matter reduction with respect to diesel fuel. The potential emission benefits induced by the presence of oxygen in fuel molecules has increased the interest in using the bio-alcohols fuel blends in CI engines such as ethanol. Although alcohols are more suitable for blending with diesel fuel, properties like lubricity, viscosity, stability, heating value and cetane number of diesel-alcohol (Diesohol) still require improvement. One of the techniques is addition of biodiesel which can improve all of these properties forming diesel-biodiesel-alcohol (ternary) blends. The blends of diesel-biodiesel-ethanol can be used in the existing CI engines without any major modifications and most significant result of using this blend is the lower emission with almost the same performance as of diesel fuel alone. The present study focused on investigation of performance and combustion characteristics of ternary fuel blend in DI diesel engine operating at different injection opening pressure (IOP). The different injection opening pressures are: 180 bar, 200 bar and 220 bar.
\end{abstract}

\section{Keywords}

Diesohol, Ternary Fuel Blends, Aromatic Compounds, Injection 
Opening Pressure, CI Engines

\section{Introduction}

The ongoing investigations and the already found analysis about the fractional replacement of fossil diesel fuel with the combination of biodiesel and ethanol in compression ignition engines found to be successful as this blend has the similar fuel properties like the commercial diesel fuel with high bio fuel content. Many scientists and investigators have studied this blend with different proportions of diesel, biodiesel and ethanol to study its suitability as a fuel in existing CI engines [1]. It was found from the detailed literature survey that a maximum of $20 \%$ biodiesel and $10 \%$ of ethanol can be added to the diesel fuel effectively. Many investigators have used soybean, rapeseed oil, Pongamia oil and waste cooking oil as an emulsifier in diesohol blend [2]. Little literature is available on the use of methyl esters of Rice bran oil and Mahuva oil blend with diesohol, hence these two biodiesels are chosen for analysis. However a detailed analysis of performance, combustion characteristics of diesel-biodiesel-ethanol blend in diesel engines appears to be scarce. Thus the aim of this work is to investigate the optimum engine parameters at which the ternary blends can be used effectively. The engine is also tested at different injection opening pressure. A lot of work has been carried on optimization of ternary blend using soybean, palm, rape seed, Jatropha biodiesels, but a very little information is available using mahuva biodiesel. So in this work an effort is done to determine experimentally the performance and combustion characteristics of the direct injection diesel engine fuelled with diesel-mahuva biodiesel blend with ethanol as an additive. The engine is also tested at different injection opening pressure.

\subsection{Scope of Biodiesel as an Alternative Fuel}

Biodiesels can be defined as "the mono alkyl esters of long chain fatty acids derived from lipid feed stock, such as vegetables and animal fats, for its use in diesel engines" [3]. Neat vegetable oils are not ideally suitable for compression ignition engines as a fuel because of durability and operational problems. The durability problems such as deposit formation, lubrication oil dilution and choking of injector tip. The Operational problems such as ignition, combustion and ability to start may restrict the use of neat vegetable oils [4]. These problems are mainly due to higher viscosity and density, which leads to poor atomization, bigger droplets, longer jet spray penetration, and low volatilities. Many efforts have been carried out to reduce the viscosity of the vegetable oils. Two different methods are used to reduce the viscosity of the oils:

1) Engine modification: Heating the fuel line, injection system modification, duel fuelling.

2) Fuel modification: Blending, Pyrolysis and micro emulsion.

Biodiesel are chemically high biodegradable, it can be mixed with any diesel at 
any ratio. It emits no sulphur oxides, a pollutant that causes acid rain and burns the lungs, eyes and throat. Global warming can be reduced by reducing the emission of carbon dioxide by using the biodiesel. Some of the advantages of using biodiesel are, absence of sulphur, absence of aromatics, lower hydrocarbon emissions, reduction of smoke and soot and reduction i carbon monoxide [5].

Biodiesel can be mixed with diesel fuels in any proportion; the blend can stable even at low temperatures. It is advisable that biodiesels can't be stored more than six months, similar to fossil diesel fuel. It can be stored in a closed container with air tight heading protecting from direct sun light, moisture and cold weather. Biodiesel separates from diesel fuel at lower temperatures and it can clog the fuel flow line, but as it warms up it liquidates [6].

Even though it has got many more advantages, it cannot be used as a sole fuel for compression ignition engine, because of its lower heating value, higher density and higher emission of $\mathrm{NO}_{\mathrm{x}}$. The higher emission of $\mathrm{NO}_{\mathrm{x}}$ is due to higher exhaust gas temperature. Due to lower heating value of biodiesel the efficiency of the engine reduces.

\subsection{Scope of Alcohols as an Alternative Fuel}

Alcohol is a bio-product extracted with the help of chemical process. Raw material for alcohol is; grains, agricultural wastes, starch, sugar and wood. Ethanol and methanol are two important alcohols. Ethanol has been used in Germany and France as early as 1894 and Brazil has utilized ethanol as a fuel since 1925 [7].

Ethanol consists of carbon, hydrogen and oxygen, since it consists of oxygen ethanol burns cleaner than fossil fuels. Emissions from ethanol are very less, particularly NOx emission which is not possible with biodiesel. Ethanol can be produced from agricultural wastes, grains, dated soda, cheese whey, grains or any other material which contains starch or sugar. Ethanol can be called as renewable fuel as it is produced from crops. Use of ethanol in the compression ignition may cause some problems such as:

1) More amount of ethanol is required to produce the rated power.

2) Low boiling point and high vapour pressure may cause vapour lock.

3) High latent heat of ethanol leads to poor mixing with air, hence need heating of intake manifold.

4) Low cetane number leads to poor combustion.

The above problems can be overcome by blending the ethanol with diesel fuel. The blend of diesel and ethanol is called as diesohol, which is the best alternative fuel for dual fuel engines. Anhydrous ethanol makes homogeneous mixture with diesel fuel but hydrous ethanol with diesel makes phase separation. This can be solved by adding emulsifier or surfactants. The maximum percentage of ethanol in the diesel fuel blend is around 15\% [8].

\section{Experimental Work}

Experiment was conducted on DI diesel engine to determine the performance 
and combustion parameters. The performance parameters like brake thermal efficiency (BTE), brake specific fuel consumption (BSFC), exhaust gas temperature (EGT) were determined. The combustion parameters like, cylinder pressure, mass fraction burn, cumulative heat release rate and net heat release were determined. The engine was run at different injection opening pressure. Different injection opening pressure: 180 bar, 200 bar and 220 bar, injection opening pressure was set by adjusting the compression of the spring and calibrated. Table 1 gives detailed Engine specifications:

\section{Materials and Methodology}

The various materials used for conducting experiment are, pure diesel fuel (D100), pure biodiesel (B100), ternary fuel blends; ternary fuel blends were prepared by blending different proportion of diesel fuel, Mahuva biodiesel and ethanol by volume. The different prepared ternary fuel blends are: D70B20E10 (B20), D60B30E10 (B30) and D50B40E10 (B40). E10 indicates 10\% of ethanol is used as an additive in the blend. The basic fuel properties of fuels were determined according to ASTM standards in Bangalore test house, Bangalore and IISC, Bangalore. The engine was run with different injection pressure (IOP) 180 bar, 200 bar and 220 bar; IOP was set by adjusting the spring pressure and was calibrated in the lab.

\section{Results and Discussions}

\subsection{Performance Characteristics}

The performance characteristics discussed in this section are brake thermal efficiency (BTE), brake specific fuel consumption (BSFC) and exhaust gas temperature (EGT).

\subsubsection{Brake Thermal Efficiency}

Figure 1 shows the variation of brake thermal efficiency of pure diesel (D100),

Table 1. Engine specifications.

\begin{tabular}{cc}
\hline Specifications & Details \\
\hline Engine type, model & Kirloskar, TV-1 \\
Number of strokes & 4 \\
Power output & $5.2 \mathrm{~kW} / 7 \mathrm{BHP}$ \\
Bore x Stroke & $87.5 \mathrm{~mm} \times 110 \mathrm{~mm}$ \\
Number of cylinders & One \\
Constant speed & $1500 \mathrm{RPM}$ \\
Orifice diameter & $20 \mathrm{~mm}$ \\
Injection pressure & $180-220$ \\
Swept volume & $0.662 \mathrm{liter}$ \\
Nozzle hole diameter & $0.223 \mathrm{~mm}$ \\
\hline
\end{tabular}




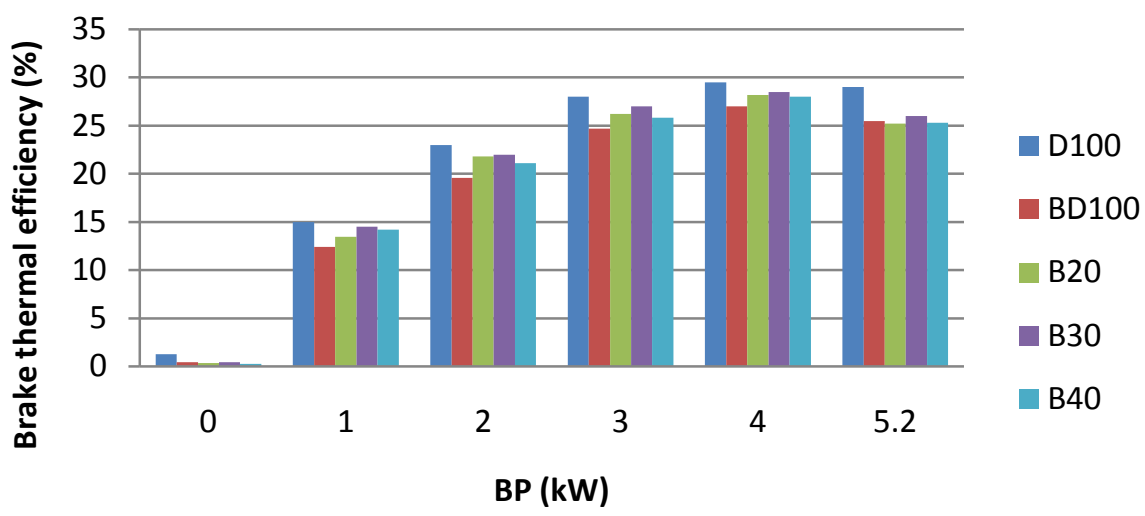

Figure 1. Brake thermal efficiency with BP.

biodiesel (BD100), and ternary fuel blends (B20, B30, B40) with brake power. BTE increases with increase in load it's due to better combustion at higher loads. BTE of the fuels follow the same trend at all loads. The BTE of D100, BD100, B20, B30 and B40 at full load are 28\%, 25\%, 26\%, 27\% and 25\% respectively. The BTE of the ternary fuel blends is almost same as that of pure diesel fuel; it may be due to leaner combustion and higher ignition delay of biodiesel and ethanol. Further increase of biodiesel proportion in the ternary blend decreases the BTE; it may be due to lower heating value, higher density and viscosity of the biodiesel. Hence ternary fuel blends with limited biodiesel proportion in the blend can be effectively used as an alternative fuel.

Figure 2 shows the variation of brake thermal efficiency of different fuels at different injection opening pressures (IOP) at full load. The brake thermal efficiency increases when the IOP increases from 180 bar to 200 bar, it is because of increased IOP leads to better atomization and complete combustion of the fuel, further increase of IOP to 220 bar leads to decrease in brake thermal efficiency, it may be due to higher IOP leads to more vaporization of the fuel and sudden rise of combustion temperature which leads to more heat loss. Hence ternary fuel blends with 200 bar IOP has better thermal efficiency. B30 at 200 bar IOP has same BTE as diesel fuel.

\subsubsection{Brake Specific Fuel Consumption}

Figure 3 shows the variation of brake specific fuel consumption (BSFC) of pure diesel fuel (D100), biodiesel (B100), ternary fuel blends (B20, B30, B40) with BP. BSFC decreases with increase in load it's due to better combustion at higher loads. BSFC of the fuels follow the same trend at all loads. The BSFC of the ternary fuel blends is slightly more than that of the diesel fuel and mahuva biodiesel it is because of lower heating value of the biodiesel and ethanol in the ternary fuel blends. Among the ternary fuel blends B30 has lowest fuel consumption.

Figure 4 shows the BSFC of various fuels and fuel blends at different Injection pressures. Figure shows that BSFC decreases with increase in IOP; it is due to higher IOP leads to better atomization and through mixing of fuels, which leads to complete combustion and hence lower fuel consumption. At 220 bar IOP the BSFC is $1 \mathrm{~kg} / \mathrm{kW}$-hr less than at 180 bar IOP for modes of fuel. Hence 


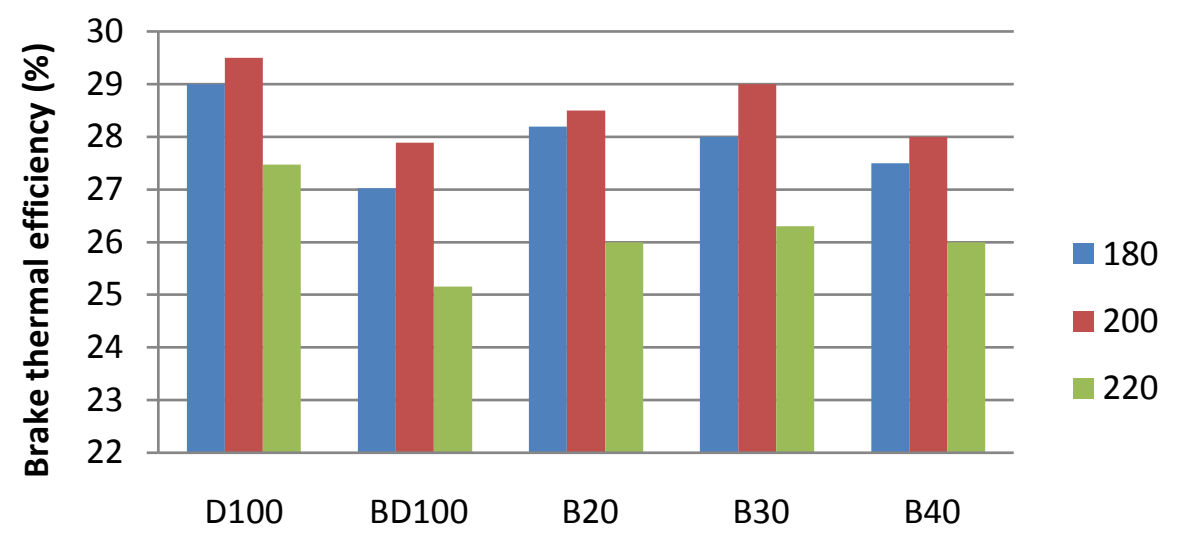

Fuel blend

Figure 2. Brake thermal efficiency with IOP at full load.

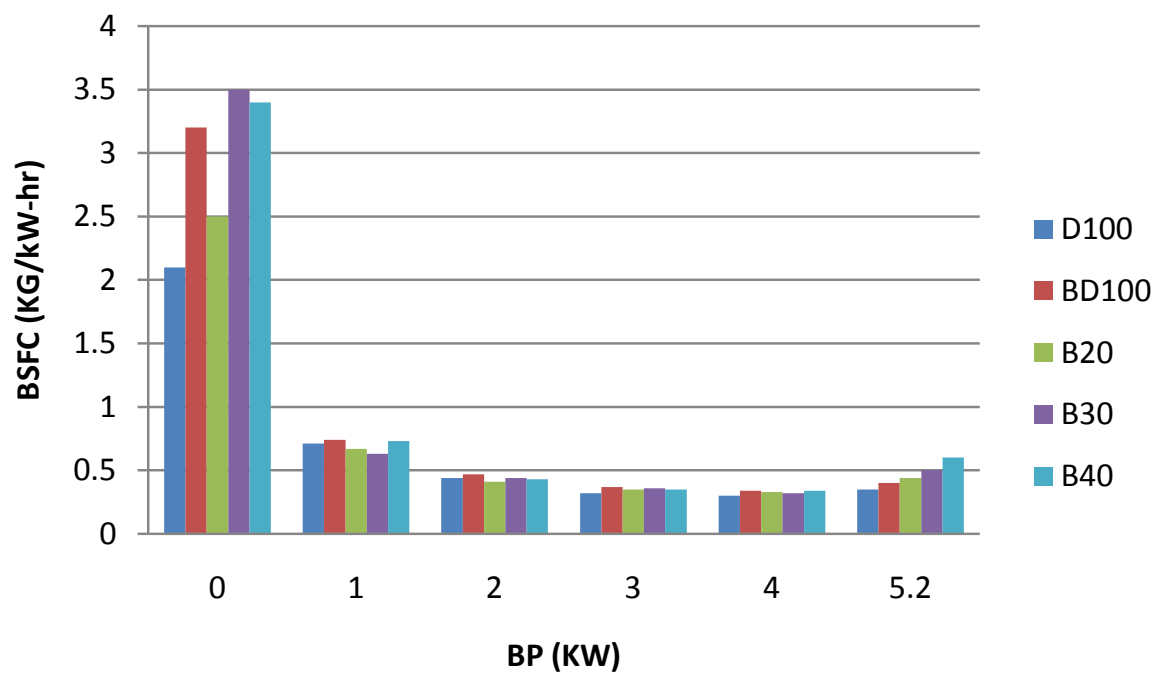

Figure 3. Brake specific fuel consumption with BP.

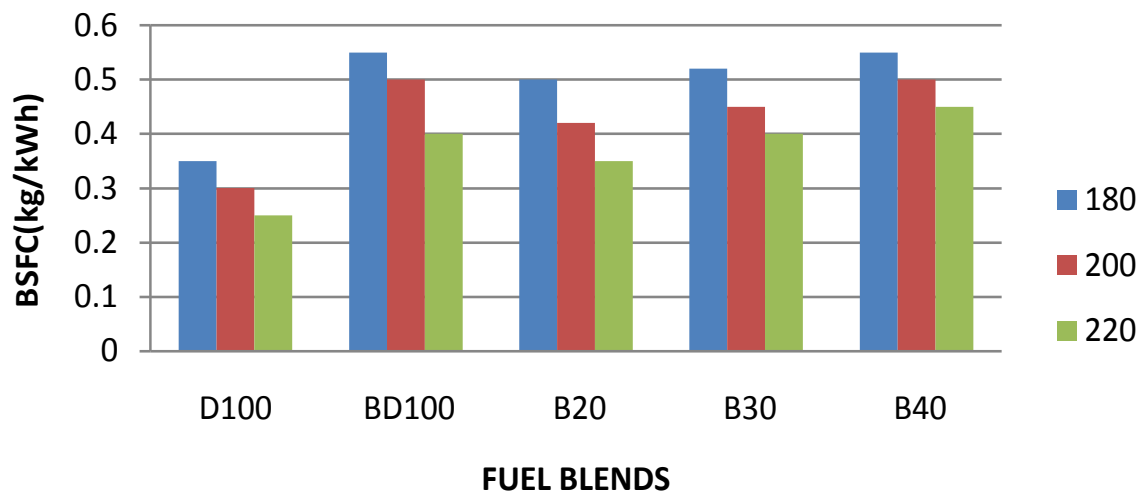

Figure 4. Brake specific fuel consumption at different IOP.

ternary fuel blends at higher IOP are suitable for engines.

4.1.3 Exhaust Gas Temperature

Figure 5 shows the variation of EGT of pure diesel fuel (D100), biodiesel 
(BD100), ternary fuel blends (B20, B30, B40). It is observed from the graph that exhaust gas temperature increases with increase in load; it is due to higher combustion temperature. EGT of ternary fuel blends are almost same as of diesel fuel at all load conditions; it is due to presence of ethanol which has high evaporative heat and low heating values, which takes off the heat from combustion chamber. At full load the EGT of all modes of fuel is around $450^{\circ} \mathrm{C}$.

Figure 6 shows the variation of EGT of various fuels at different IOP at full load. It shows that EGT reduces with increase in IOP; it is due to better atomization, complete combustion of the fuel and effective heat conversion, which leads to less heat escape in to the exhaust gas. Hence higher IOP are preferable for ternary fuel blends concerned to EGT.

\subsection{Combustion Characteristics}

The combustion characteristic discussed in this section is cylinder pressure, mass fraction burn rate, cumulative heat release and net heat release.

\subsubsection{Cylinder Pressure}

Figure 7 shows the peak cylinder pressure of the engine with respective crank angle.

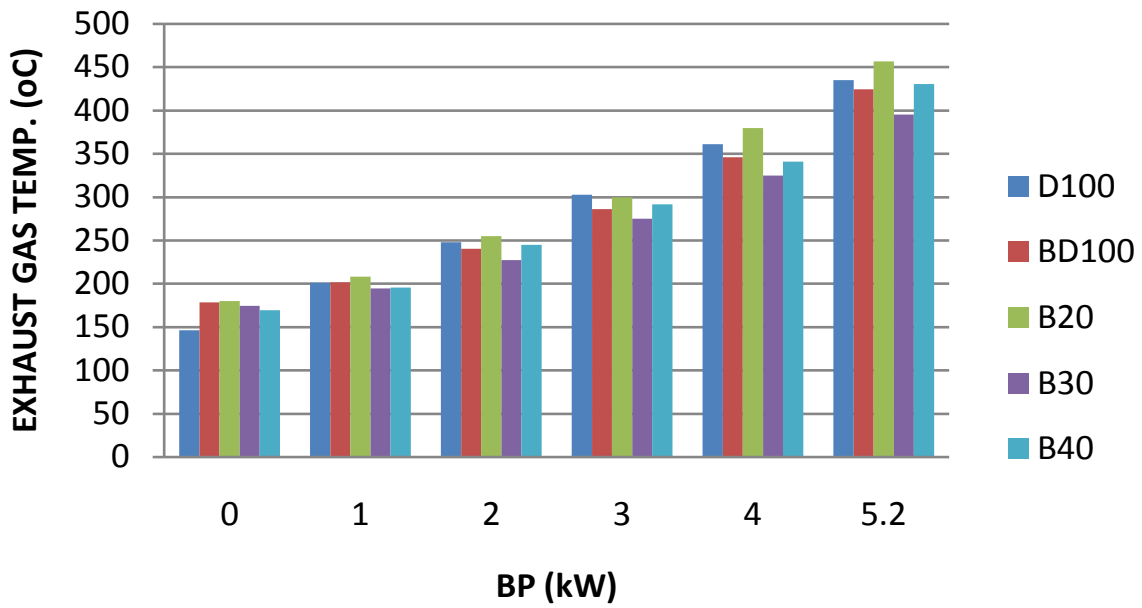

Figure 5. Exhaust gas temperature with BP.

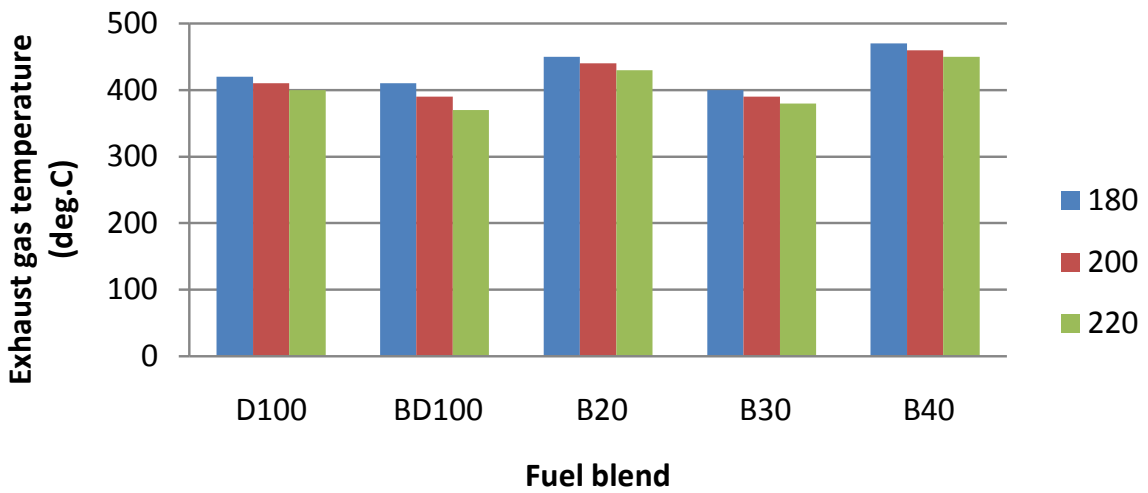

Figure 6. Exhaust gas temperature at different IOP. 
For D100, BD100, B20, B30 and B40 the peak cylinder pressure is 68.48, 70.20, $68.18,68.46$ and 68.40 bar respectively and occurs at the same crank angle 370 deg. The peak cylinder pressure of the ternary fuel blends is same as D100; it is due to the presence of ethanol in the ternary blend leads to superior fuel mixing and atomization which leads to lower ignition delay (ID) of the ternary fuel blends. It shows that, peak cylinder pressure increases with increase in biodiesel proportion in the ternary fuel blend; it is due to higher cetane number and leaner combustion of biodiesel.

Figures 8-10 show the peak cylinder pressure at different injection opening pressure (IOP), 180 bar, 200 bar and 220 bar respectively. As IOP increases peak pressure decreases, it is due to higher IOP leads to shorter ignition delay, which in turn causes incomplete combustion and hence combustion efficiency falls down. B100 has highest peak pressure of 70.20 bar at 180 bar. It is due to leaner

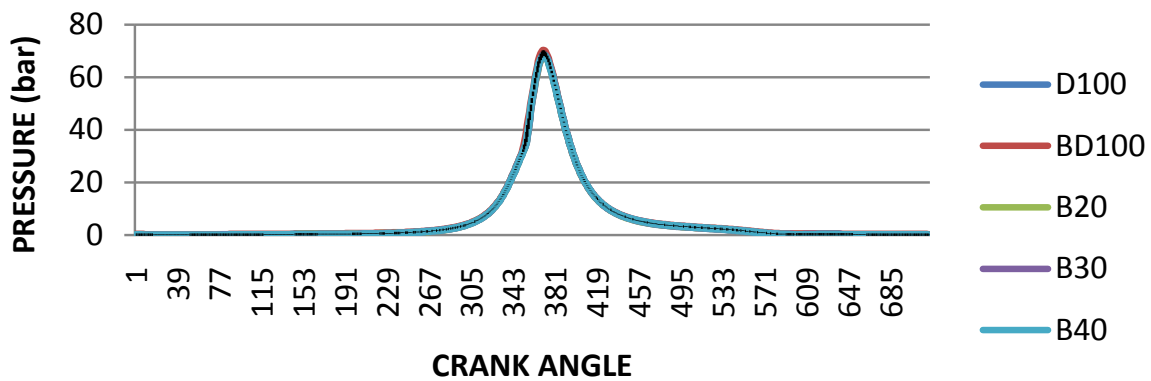

Figure 7. Cylinder pressure with crank angle.

CYLINDER PRESSURE AT 180 BAR IOP

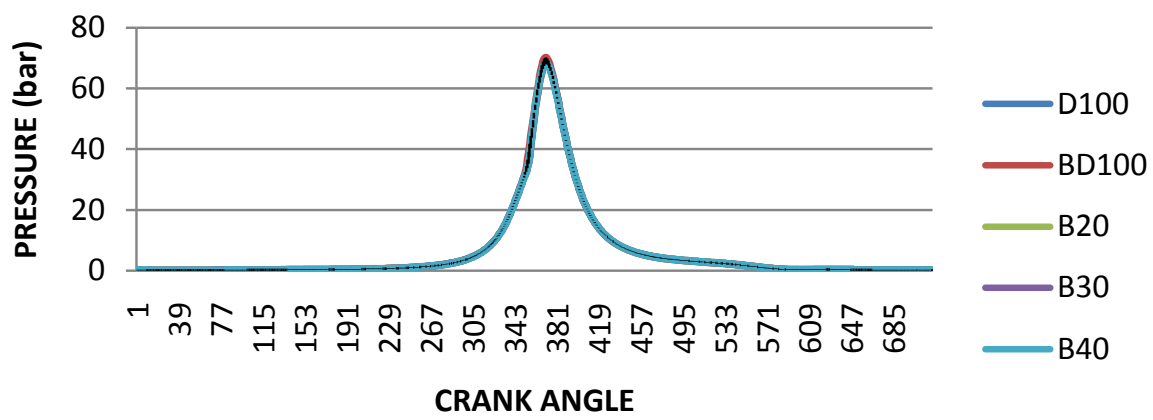

Figure 8. Cylinder pressure with CA at 180 bar IOP.

\section{CYLINDER PRESSURE AT 200 BAR IOP}

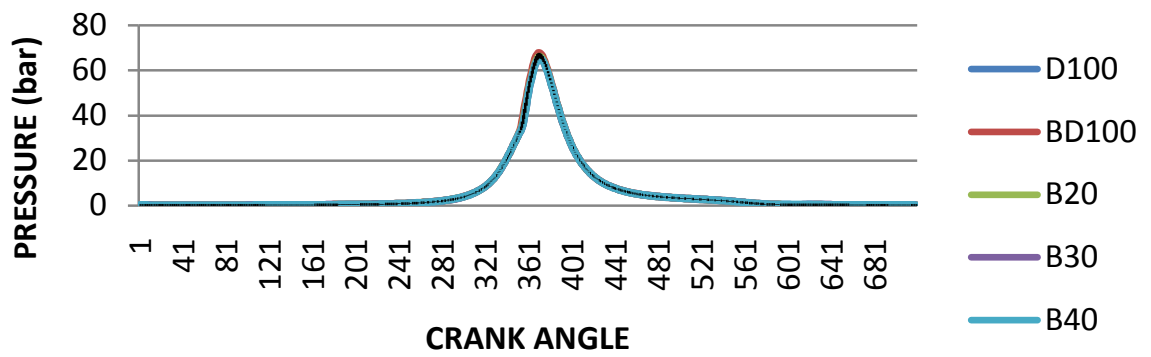

Figure 9. Cylinder pressure with CA at 200 bar IOP. 


\section{CYLINDER PRESSURE AT 220 BAR IOP}

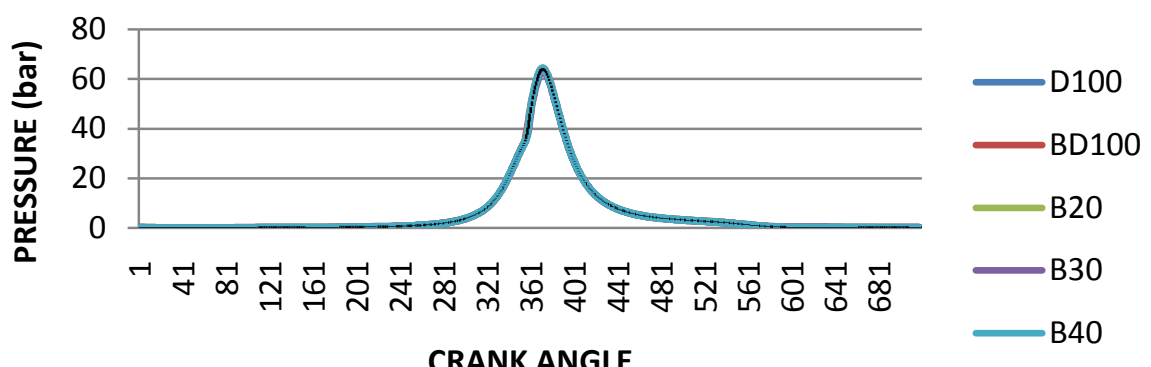

Figure 10. Cylinder pressure with CA at 220 bar IOP.

combustion and higher cetane number of the biodiesel. Among the ternary fuel blends B30 at 180 bar IOP has highest peak cylinder pressure which is almost same as D100.

\subsubsection{Mass Fraction Burn}

Figure 11 shows the variation of mass fraction burn in percentage with crank angle of various test fuels; D100, BD100, B20, B30 and B40. MFB curves follow the S-shape and all the fuels follow the same trend. MFB curves of D100, B20 and $\mathrm{B} 30$ coincides, it means both the fuels have same $\mathrm{CD}$ and heat release rate of D100. The MFB curves for B100 and B40 are distinct from that of D100, which means they have higher $\mathrm{CD}$. So B20 and B30 are the better blends as compared to B100 and B30, the similar results were obtained by B. K. Venkanna, et al.

Figures 12-14 show variation of MFB with crank angle at 180 bar, 200 bar and 220 bar IOP respectively. All the graphs follow the same trend at 180 and 200 bar IOP but little deviation is found at 220 bar IOP. At 200 bar IOP the MFB curve of B30 coincides with D100, which means B30 has similar burning rate as that of pure diesel fuel. Hence B30 is suitable ternary fuel at 200 bar IOP compared with other fuels.

\subsubsection{Cumulative Heat Release}

Figure 15 shows the variation of cumulative heat release of D100, BD100, B20, B30 and B40 with crank angle at 180 bar injection pressure. The graph shows all the modes of fuels fallow the same trend of heat release, and the maximum cumulative heat release for all the fuels is around $1.3 \mathrm{~kJ}$. The maximum crank angle at which the maximum cumulative heat is released is around $480 \mathrm{deg}$. Hence the cumulative heat release of ternary fuel blend is almost same as that of pure diesel fuel; it may be due to leaner combustion of the biodiesel fuel and higher latent heat of ethanol.

Figures 16-18 show the cumulative heat release (CHR) at different injection pressure, 180 bar, 200 bar and 220 bar. The graph shows CHR increases with increase in injection pressure it may be due to higher IOP, which leads to more atomization and ensures complete combustion.

\subsubsection{Net Heat Release Rate}

Figures 19-21 show variation of net heat release at different injection pressure 


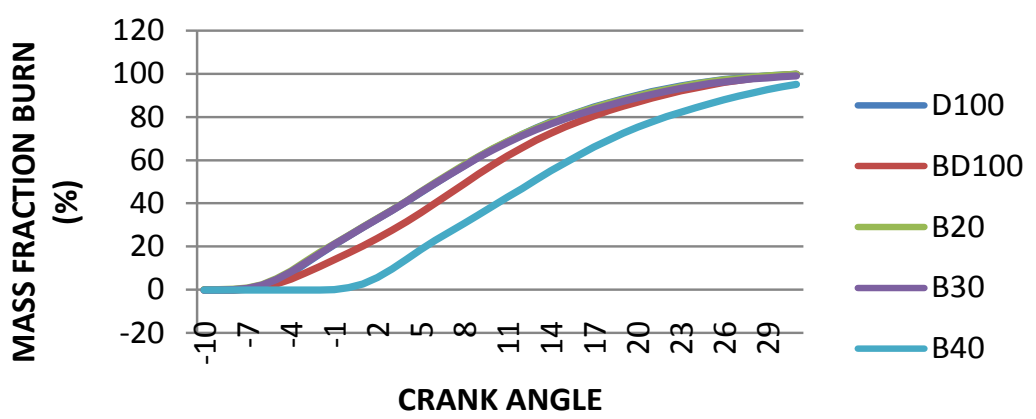

Figure 11. Variation of mass fraction burn with CA of various fuels.

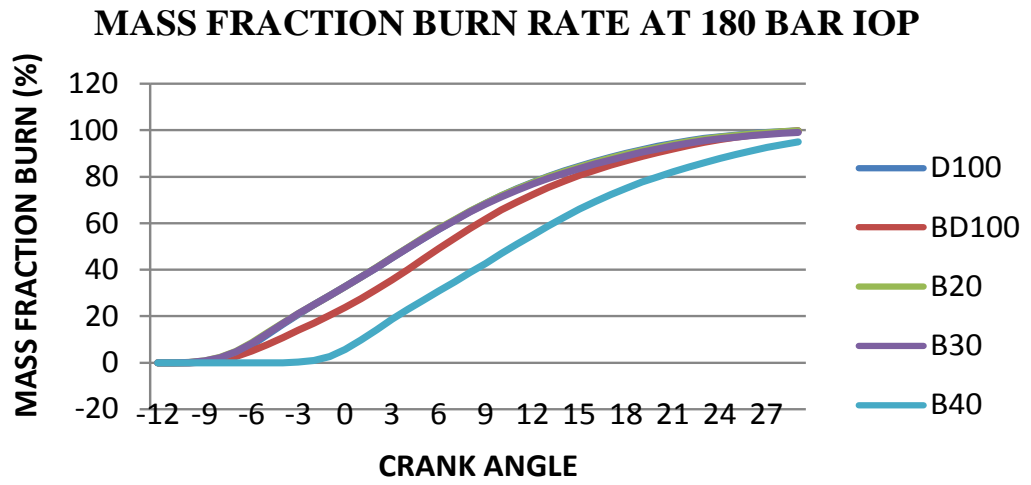

Figure 12. Variation of mass fraction burn with crank angle at 180 bar.

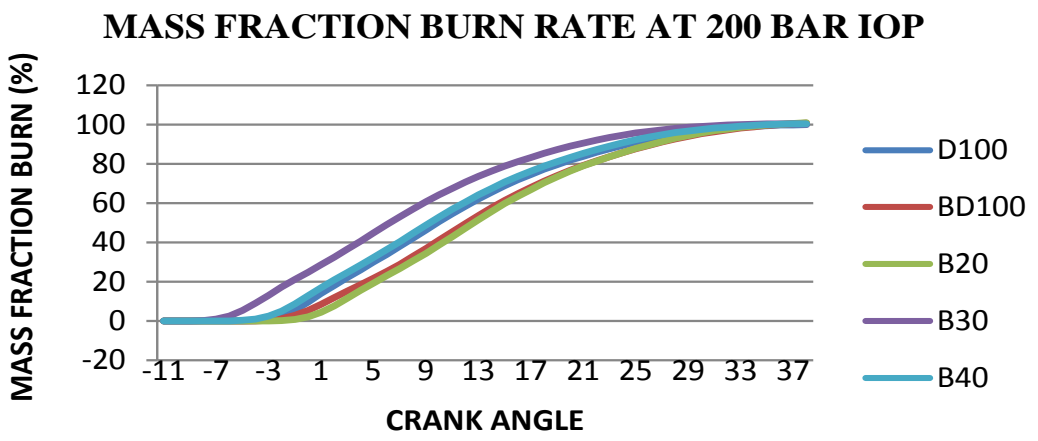

Figure 13. Variation of mass fraction burn with crank angle at 200 bar.

MASS FRACTION BURN RATE AT 220 BAR IOP

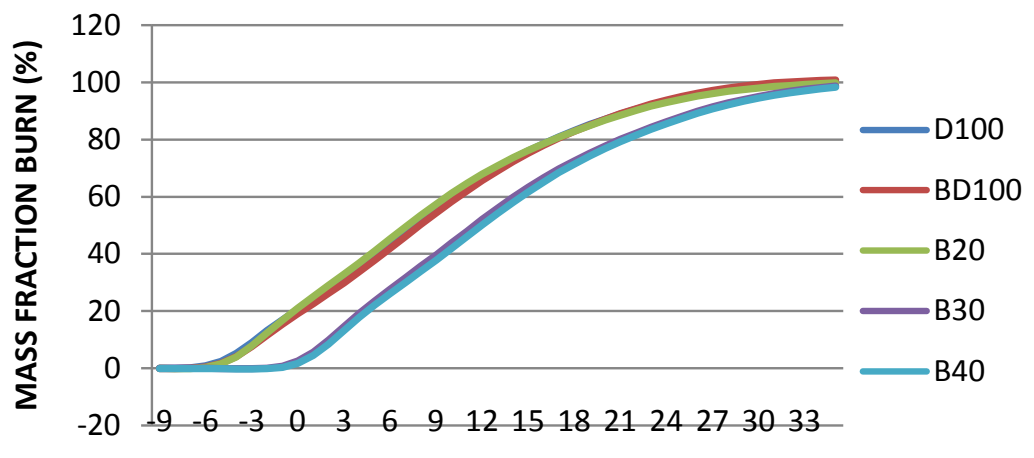

CRANK ANGLE

Figure 14. Variation of mass fraction burn with crank angle at 220 bar. 


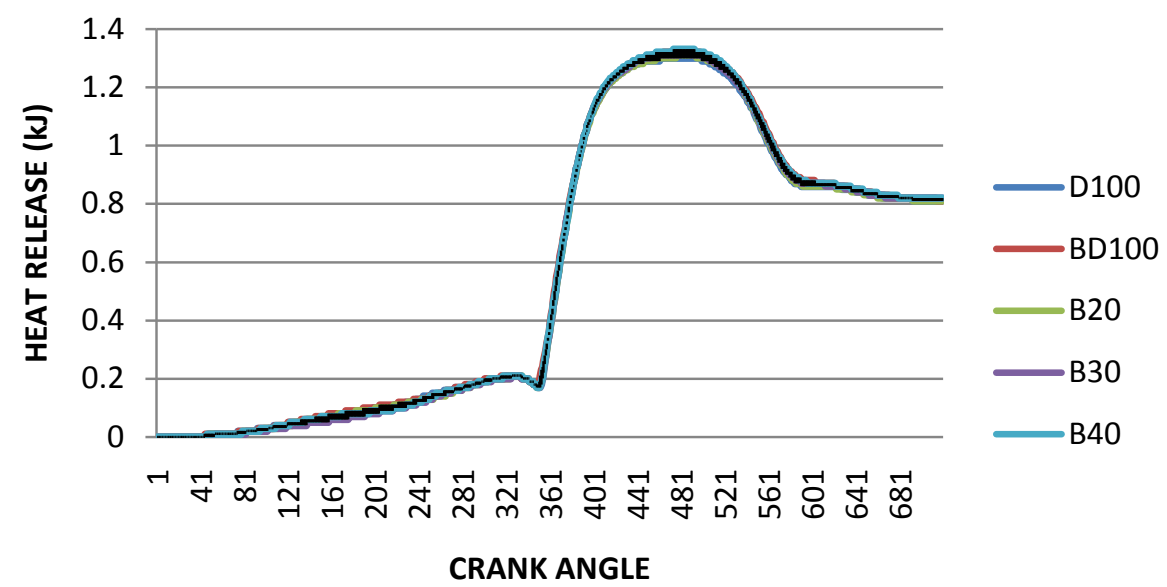

Figure 15. Variation of cumulative heat release with crank angle.

CUMULATIVE HEAT RELEASE AT 180 BAR

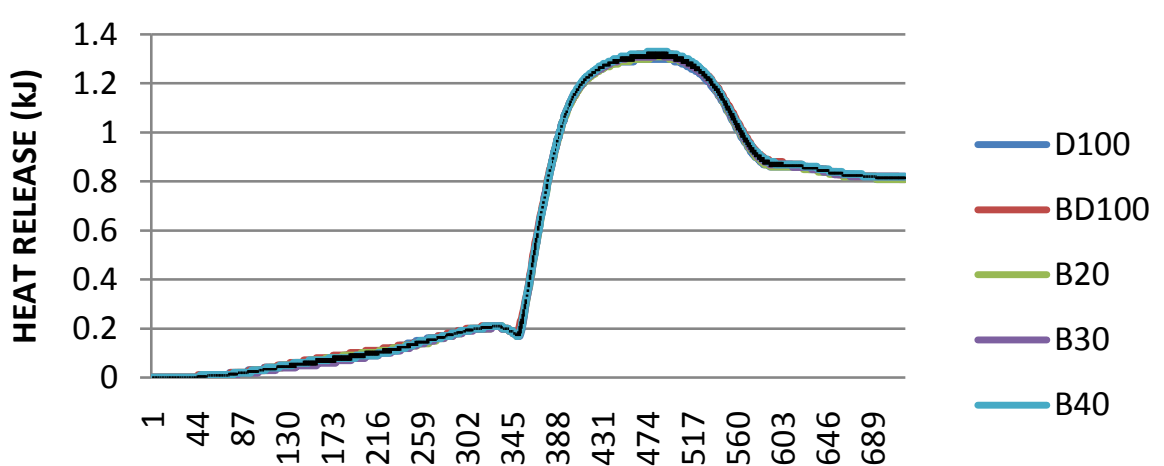

CRANK ANGLE

Figure 16. Cumulative heat release at 180 bar IOP.

\section{CUMULATIVE HEAT RELEASE AT 200 BAR IOP}

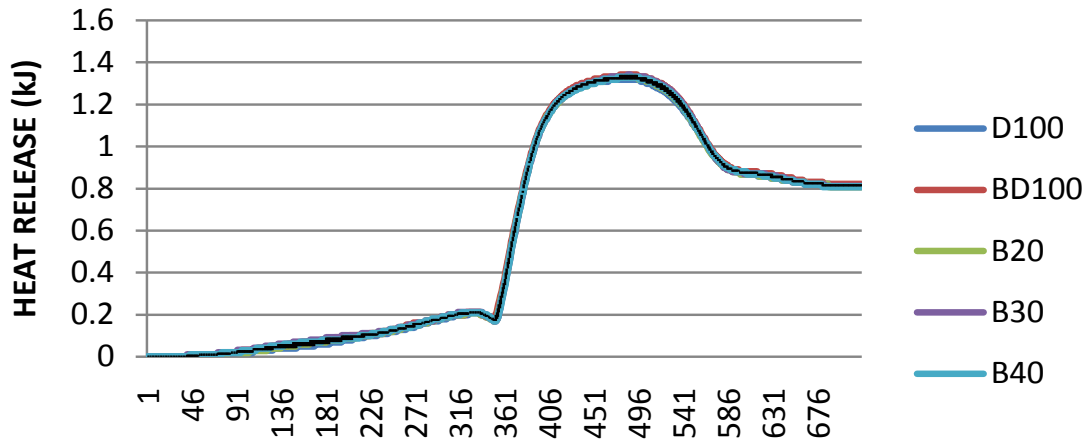

CRANK ANGLE

Figure 17. Cumulative heat release at 200 bar IOP.

(IOP), 180 bar, 200 bar and 220 bar respectively. Max. NHR occurs at $355-367$ CA, for different tested fuels. It can observe that as IOP increases NHR increases; it is due to when injection pressure increases the diameter of fuel particles small, and air fuel mixture becomes better during ignition period. But, higher 


\section{CUMULATIVE HEAT RELEASE AT 220 BAR IOP}

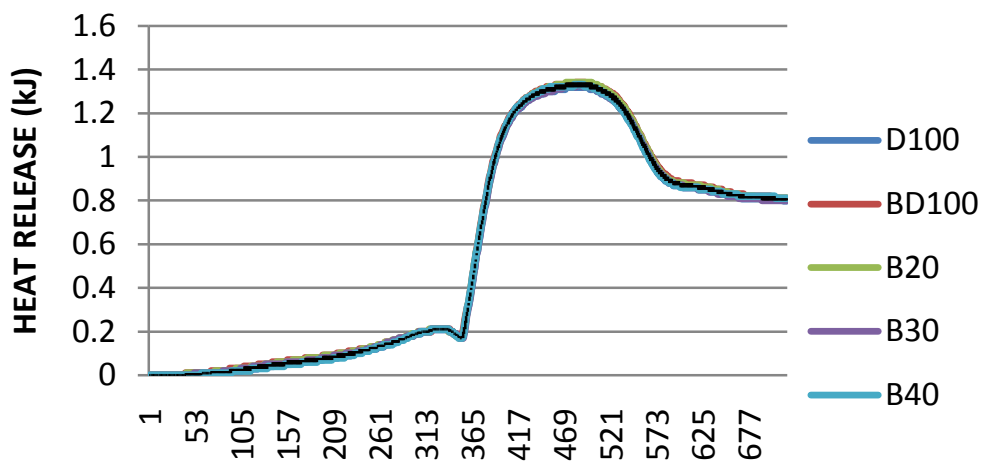

CRANK ANGLE

Figure 18. Cumulative heat release at 220 bar IOP.

\section{NET HEAT RELEASE AT 180 BAR IOP}

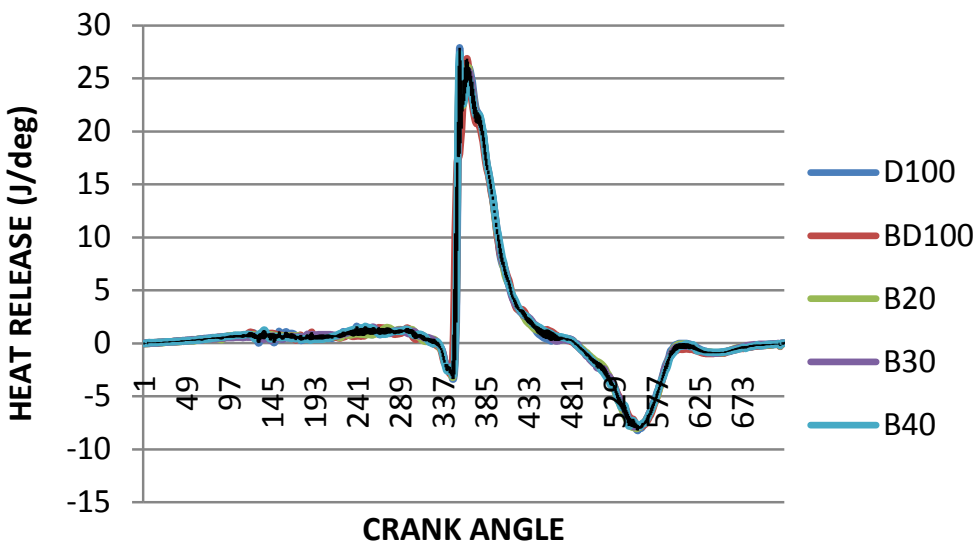

Figure 19. Net heat with CA at 180 bar IOP.

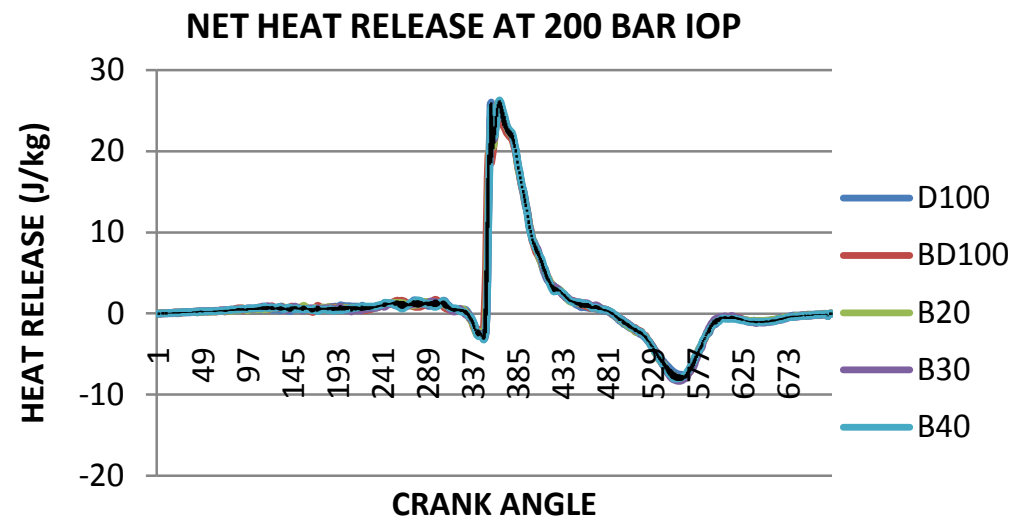

Figure 20. Net heat with CA at 200 bar IOP.

injection pressure leads shorter ignition delay, which in turn decreases the possibilities of homogeneous mixture and causes the incomplete combustion. Maximum NHR can be obtained at higher injection pressure. B30 releases maximum NHR, 28.83 at 200 bar IOP. 
NET HEAT RELEASE AT 220 BAR IOP

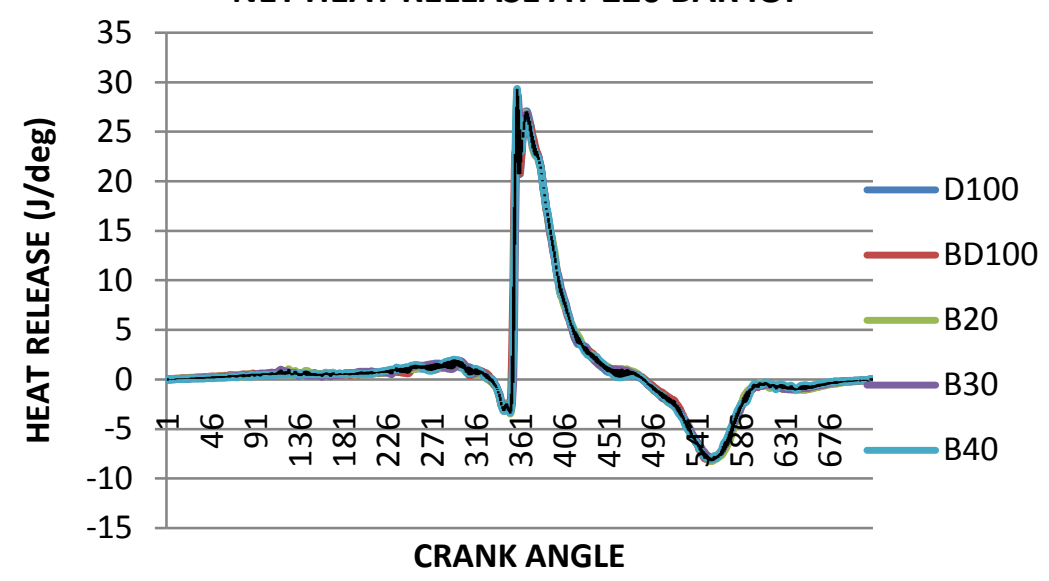

Figure 21. Net heat with CA at 220 bar IOP.

\section{Conclusions}

- Brake thermal efficiency of the ternary fuel blends is slightly less than the pure diesel fuel. Among the ternary fuel blends, B30 has higher BTE of $27 \%$. BTE increases with increase in IOP.

- Brake specific fuel consumption of the ternary fuel blends is greater than the pure diesel fuel and pure mahuva biodiesel. B30 gives lowest fuel consumption of $0.3 \mathrm{~kg} / \mathrm{kW}$-h. BSFC reduces with increase in IOP.

- Exhaust gas temperature reduces with increase in IOP; B20 has lowest EGT. At 180 bar B20 has $450 \mathrm{deg}$ C. whereas at 220 bar it is $430 \mathrm{deg}$ C.

- Peak cylinder pressure for pure Mahuva biodiesel is greater than diesel and ternary fuel blend. Peak cylinder pressure reduces as IOP increases.

- B30 has the similar mass fraction burn as that of diesel fuel.

- Cumulative heat release is more for biodiesel and ternary fuel blends as compared with diesel fuel. Cumulative heat release is more at higher injection opening pressures. CHR increased by $1.5 \%$ to $2 \%$ when IOP increased from 180 bar to 220 bar.

- Net heat release rate increases with increase in IOP. Maximum net heat occurs at 355 - 357 CA. B30 has maximum net heat of 28.83 at 200 bar IOP.

\section{References}

[1] Ajay, E.A., et al. (2002) A Study of Some Fuel Properties of Local Ethanol Blended with Diesel Fuel. Agricultural Engineering International: CIGR Journal of Scientific Research and Development, Manuscript EE 01, Vol. IV.

[2] Agarwal, A.K. (2007) Bio Fuels (Alcohols and Biodiesel) Applications as Fuels for Internal Combustion Engines. Progress in Energy and Combustion Science, 33, 233-271. https://doi.org/10.1016/j.pecs.2006.08.003

[3] Ajav, E.A., Sing, B., et al. (1998) Performance of a Stationary Diesel Engine Using Vaporised Ethanol as Supplementary Fuel. Biomass Bio Energy, 15, 493-502. https://doi.org/10.1016/S0961-9534(98)00055-5

[4] Hansen, A.C., et al. (2005) Ethanol-Diesel Fuel Blends-A Review. Bio Resource Technology, 96, 277-285. https://doi.org/10.1016/j.biortech.2004.04.007 
[5] Cheenkachorn, K., et al. (2010) An Investigation on Diesel-Ethanol-Biodiesel Blends for Diesel Engines: Part Imulsion Stability and Fuel Properties. Energy Sources, Part A: Recovery, Utilization, and Environmental Effects, 32, 637-644. https://doi.org/10.1080/15567030903059608

[6] Hulwan, D.B., et al. (2011) Performance, Emission and Combustion Characteristics of a Multicylinder DI Diesel Engine Running on Diesel-Ethanol-Bio Diesel Blends of High Ethanol Content. Applied Energy, 88, 5042-5055. https://doi.org/10.1016/j.apenergy.2011.07.008

[7] Barabas, I., et al. (2010) Performance and Emission Characteristics of a CI Engine Fuelled with Diesel-Biodiesel Bio Ethanol Blends. Fuel, 89, 3827-3832. https://doi.org/10.1016/j.fuel.2010.07.011

[8] Venkata Subbaiah, G., et al. (2010) Rice Bran Oil Biodiesel as an Additive in Diesel-Ethanol Blends for Diesel Engines. IJRRAS, 3, 334-342.

\section{Submit or recommend next manuscript to SCIRP and we will provide best} service for you:

Accepting pre-submission inquiries through Email, Facebook, LinkedIn, Twitter, etc. A wide selection of journals (inclusive of 9 subjects, more than 200 journals)

Providing 24-hour high-quality service

User-friendly online submission system

Fair and swift peer-review system

Efficient typesetting and proofreading procedure

Display of the result of downloads and visits, as well as the number of cited articles Maximum dissemination of your research work

Submit your manuscript at: http://papersubmission.scirp.org/

Or contact wjet@scirp.org 